\title{
Effect of Deformation Mode on the Wear Behavior of NiTi Shape Memory Alloys
}

\author{
Lina Yan $^{1} \cdot$ Yong Liu ${ }^{1}$
}

Published online: 5 May 2016

(C) ASM International 2016

\begin{abstract}
Owing to good biocompatibility, good fatigue resistance, and excellent superelasticity, various types of bio-medical devices based on NiTi shape memory alloy (SMA) have been developed. Due to the complexity in deformation mode in service, for example NiTi implants, accurate assessment/prediction of the surface wear process is difficult. This study aims at providing a further insight into the effect of deformation mode on the wear behavior of NiTi SMA. In the present study, two types of wear testing modes were used, namely sliding wear mode and reciprocating wear mode, to investigate the effect of deformation mode on the wear behavior of NiTi SMA in both martensitic and austenitic states. It was found that, when in martensitic state and under high applied loads, sliding wear mode resulted in more surface damage as compared to that under reciprocating wear mode. When in austenitic state, although similar trends in the coefficient of friction were observed, the coefficient of friction and surface damage in general is less under reciprocating mode than under sliding mode. These observations were further discussed in terms of different deformation mechanisms involved in the wear tests, in particular, the reversibility of martensite variant reorientation and stress-induced phase transformation, respectively.
\end{abstract}

Keywords NiTi shape memory alloy $\cdot$ Wear $\cdot$ Martensite Austenite $\cdot$ Sliding $\cdot$ Reciprocating

Yong Liu

MLIUY@ntu.edu.sg

1 School of Mechanical and Aerospace Engineering, Nanyang Technological University, 50 Nanyang Avenue, Singapore 639798, Singapore

\section{Introduction}

Benefitted from good biocompatibility, fatigue resistance, corrosion resistance, and superelasticity, NiTi SMA has been considered as a superior alloy in many bio-medical applications. Bio-medical devices such as NiTi marrow needles, NiTi superelastic arch wire, and shape memory attachment for partial denture have been successfully developed [1-3]. Furthermore, NiTi SMA was widely researched for implants since their mechanical properties are close to those of cortical bones [4]. For example, applications such as joint replacements, bone plates, and spine fracture fixation were developed [5-7]. Good biocompatibility of NiTi SMA was attributed to the surface oxide film, which is mainly composed of titanium oxide. This thin layer of titanium oxide acts as a barrier to prevent nickel ion release [8]. Wear may remove the surface oxide film and therefore affect the reliability of the medical devices that are implanted in the human body. Removal of the surface oxide film can trigger inflammation of human body or cause serious health problem. However, due to the complex deformation mode involved in the applications, prediction of surface wear process of NiTi is extremely challenging. Understanding of the wear process of NiTi SMA under different deformation modes can help provide a guideline in monitoring the surface wear conditions.

Majority of wear studies on NiTi SMA have focused on sliding wear behavior. For example, when tested under pinon-disk and pin-on-ring modes, sliding wear behavior of NiTi SMA was compared with conventional wear-resistant materials including 304 steel, BS11, and class D tire steel [9-11]. The superior wear resistance of NiTi SMA was attributed to the deformation strain accommodation through detwinning or stress-induced martensitic transformation (SIMT) process. In addition, fretting wear behavior 
of NiTi SMA has also been studied [12-14]. Better fretting wear resistance of NiTi SMA as compared to that of GCr15 steel was attributed to reversible phase transformation process.

It is known that, different from conventional dislocation mechanism, the deformation of NiTi SMA can be achieved through domain switching/reorientation and SIMT. When tested under different wear modes, these deformation mechanisms may proceed differently which in turn lead to different paces of surface degradation process. This is important for understanding/predicting the surface wear processes of the wear-bearing devices which involve significantly different stress conditions. However, such understanding is missing. Hence, a systematic research on the effect of deformation mode on the wear behavior of NiTi SMA is needed both experimentally and theoretically.

The present study has compared the wear behavior of NiTi SMAs under two types of wear test modes: one is a ball-on-disk sliding wear mode and another is a reciprocating wear mode. Wear behavior in both martensitic and austenitic NiTi SMAs was examined under different applied loads and sliding speeds. Coefficients of friction and surface damages as a function of sliding speed, applied load, and wear test cycles were examined. We paid particular attention to the values of coefficient of friction (COF) after 100 wear cycles, which is in the initial process of wear, and those after 1000 wear cycles when the value of COF becomes stable. The surface wear features were imaged using a confocal microscope. For both of martensite and austenite, lower coefficients of friction and less surface damage were observed when tested under reciprocating wear mode than that under sliding wear mode. This was further discussed with respect to the reversibility of martensite variant reorientation and stress-induced phase transformation versus deformation mode involved in the wear test. An explanation for the effect of wear mode on the wear behavior of NiTi SMA was proposed, which might help guide further study on the prediction of wear process of SMA in applications such as bone plates and spine fracture fixation which involve complex stress conditions and uneven distribution of wear damages.

\section{Experimental Methods}

In the present study, two types of NiTi SMA were studied: a commercial $\mathrm{Ni}-48.2$ at\% $\mathrm{Ti}$ forged ingot and a 1-mmthick Ni-50.9 at\% Ti plate from Memry Corp. Wear tests were all conducted at $20{ }^{\circ} \mathrm{C}$ at which the ingot sample is in martensitic state, while the plate sample is in austenitic state. The transformation temperatures were determined using a Q200 differential scanning calorimeter (DSC) from TA instruments, with a heating rate of $2{ }^{\circ} \mathrm{C} / \mathrm{min}$. For the ingot sample, the martensitic starting $\left(M_{\mathrm{s}}\right)$ and finishing $\left(M_{\mathrm{f}}\right)$ temperatures are 56 and $36{ }^{\circ} \mathrm{C}$, while the austenitic starting $\left(A_{\mathrm{s}}\right)$ and finishing $\left(A_{\mathrm{f}}\right)$ temperatures are 66 and $92{ }^{\circ} \mathrm{C}$, respectively. For the NiTi plate which was in annealed condition, the $M_{\mathrm{s}}, M_{\mathrm{f}}, A_{\mathrm{s}}$, and $A_{\mathrm{f}}$ temperatures are $-18,-44,-16$, and $6{ }^{\circ} \mathrm{C}$, respectively. Tensile tests were conducted on an Instron $5569 \mathrm{UT} \mathrm{M} / \mathrm{C}$ at $20{ }^{\circ} \mathrm{C}$, and the strain rate was at $0.001 \mathrm{~s}^{-1}$. Dog bone-shaped samples with dimension of $120 \mathrm{~mm} \times 2 \mathrm{~mm} \times 1 \mathrm{~mm}$ were used for the tensile tests.

For wear tests, samples with dimension of $10 \mathrm{~mm} \times 10 \mathrm{~mm} \times 1 \mathrm{~mm}$ were ground and polished to remove the pre-existing surface oxide layer. They were then held at $150{ }^{\circ} \mathrm{C}$ for $10 \mathrm{~min}$ to release the residual stress. Thereafter, sample surface was examined using a DI3000 atomic force microscope (AFM) in the tapping mode. Three different areas of $10 \times 10 \mu \mathrm{m}^{2}$ were arbitrarily selected for scanning. Only samples with average surface roughness value ( $\mathrm{Ra}$ ) below $15 \mathrm{~nm}$ were used in wear studies. Nano-tribometer was used under ball-on-disk contact mode. Alumina counter ball having a diameter of $2 \mathrm{~mm}$ was used. Sliding wear and reciprocating wear tests were conducted under different applied loads and sliding speeds. The major difference between these two types of wear mode is that under sliding mode, the sliding alumina ball moves in the same direction all the time, while in the reciprocating test, the alumina ball moves back and forth in opposite directions during wear test. The medium-load cantilever was used when the applied load was at 25, 50, and $75 \mathrm{mN}$, while the high-load cantilever was used when the applied load was at 100, 200, 300, 400, and $500 \mathrm{mN}$. In addition, two sliding speeds (denoted as S1 and S2) were used and are listed in Table 1. During wear tests, coefficient of friction was recorded as a function of wear cycles. After each test, surface wear features were further examined using Nikon Eclipse L150 laser confocal microscope.

\section{Results}

\section{Stress-Strain Curves of Stable Martensitic and Austenitic NiTi SMAs}

Figure 1 shows the stress-strain curves of both the martensitic (Fig. 1a) and the austenitic (Fig. 1b) samples tested at $20{ }^{\circ} \mathrm{C}$. A clear stress-plateau was found in the stress-strain curve shown in Fig. 1a. The plateau stress for detwinning is about $157 \mathrm{MPa}$. It is known that the martensite deformation proceeds in four stages. In stage I, the applied stress is below the critical stress for detwinning and martensite deforms mainly elastically. In stage II, martensite deforms through variant reorientation leading to detwinning which results in a stress-plateau. In stage III, 
Table 1 Summary of experimental parameters

\begin{tabular}{lll}
\hline Parameter & Unidirectional sliding wear mode & Reciprocating wear mode \\
\hline Sliding speed $(\mathrm{mm} / \mathrm{s})$ & $1.25(\mathrm{~S} 1), 2.5(\mathrm{~S} 2)$ & $1.5(\mathrm{~S} 1), 2.5(\mathrm{~S} 2)$ \\
Wear track $(\mathrm{mm})$ & Circular wear track & Linear wear track \\
& Radius at 0.25 & Half amplitude at 0.25
\end{tabular}

Wear cycles

Applied load (mN)
Up to 1000 cycles

Martensitic sample: 50, 100, 200, 300, 400, 500

Austenitic sample: 25, 50, 75, 100, 200, 300
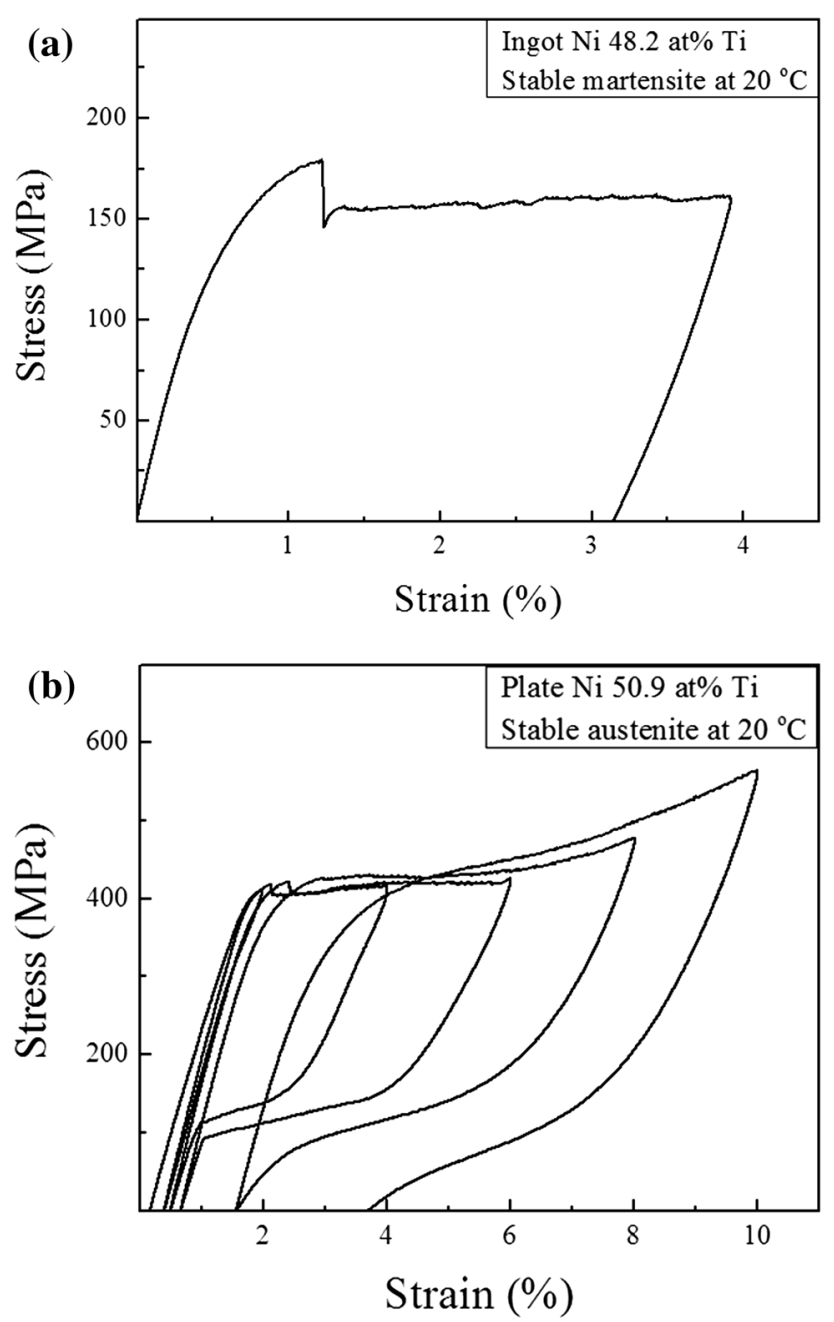

Fig. 1 Stress-strain curves of stable a martensitic and $\mathbf{b}$ austenitic samples

martensite twins are mostly detwinned and detwinned martensite deforms further elastically. In stage IV, stress exceeds the yield stress of detwinned martensite and the detwinned martensite deforms plastically leading to final fracture.

For the austenitic sample, the deformation strains of 4 and $6 \%$ were nearly fully recovered upon unloading. With further increasing the deformation strain to 8 and $10 \%$, residual strains of about 1.6 and $3.8 \%$ were observed. In general, deformation of austenitic SMA also proceeds in four stages. In stage I, the applied stress is below the critical stress for stress-induced martensitic transformation which is at about $420 \mathrm{MPa}$ in the present sample, and the austenite deforms elastically. In stage II, when stress exceeds this critical stress, austenite transforms to martensite through an SIMT and is accompanied with a stress-plateau. In stage III, stress exceeds the stress-plateau but is still below the yield stress of stress-induced martensite (SIM) and hence the SIM deforms elastically. In stage IV, the stress exceeds the yield stress of SIM and it deforms plastically leading to final fracture.

Since the Young's modulus of the stable austenitic sample is higher than that of the martensitic sample, the contact stress of the austenitic sample is higher when tested under the same applied load. Hence different applied loads were selected for testing martensitic and austenitic NiTi SMAs.

The average elastic contact stress was estimated using Hertzian elastic contact model with the following equations $[15,16]$ :

$\sigma^{3}=\left[6 F_{n}\left(E^{*}\right)^{2}\right] /\left(\pi^{3} R^{2}\right)$

$1 / E^{*}=\left(1-v_{1}^{2}\right) / E_{1}+\left(1-v_{2}^{2}\right) / E_{2}$,

where $\sigma$ is the contact stress, $F_{\mathrm{n}}$ is the applied load, and $R$ is the radius $(1 \mathrm{~mm})$ of the contact ball. The $E_{1}$ and $E_{2}$ are the elastic modulus of the alumina counter ball and stable martensite or austenite, with the values of 375,26 , and $75 \mathrm{GPa}$, respectively. The $v_{1}$ and $v_{2}$ are the Poisson's ratios, with the values of 0.23 and 0.33 for the alumina counter ball and NiTi SMA, respectively.

For the martensitic sample, with an applied load of 50 $\mathrm{mN}$, the calculated average contact stress is around $190 \mathrm{MPa}$. This value is slightly higher than the experimentally determined critical stress for detwinning under tension mode (about $180 \mathrm{MPa}$ ) but much lower than the reported yield stress of detwinned martensite which is at around 630-800 MPa [17, 18]. Therefore, when tested under an applied load of $50 \mathrm{mN}$, elastic deformation is the main deformation mode in the wear test. 
For the stable austenitic NiTi SMA, with applied loads of 25,50 , and $75 \mathrm{mN}$, the calculated contact stresses are 286, 360, and $412 \mathrm{MPa}$, respectively. Hence, elastic deformation likely dominates the wear process when tested under applied loads below $75 \mathrm{mN}$.

\section{Wear Behavior Under Sliding Wear Mode}

\section{Martensitic NiTi SMA}

\section{(1) Coefficient of friction}

For the martensitic sample, two typical trends in the coefficient of friction as a function of wear cycles are shown in Fig. 2. Figure 3 summarizes the values of the coefficient of friction after 100 and 1000 wear cycles as a function of applied load and sliding speed. Terms of initial
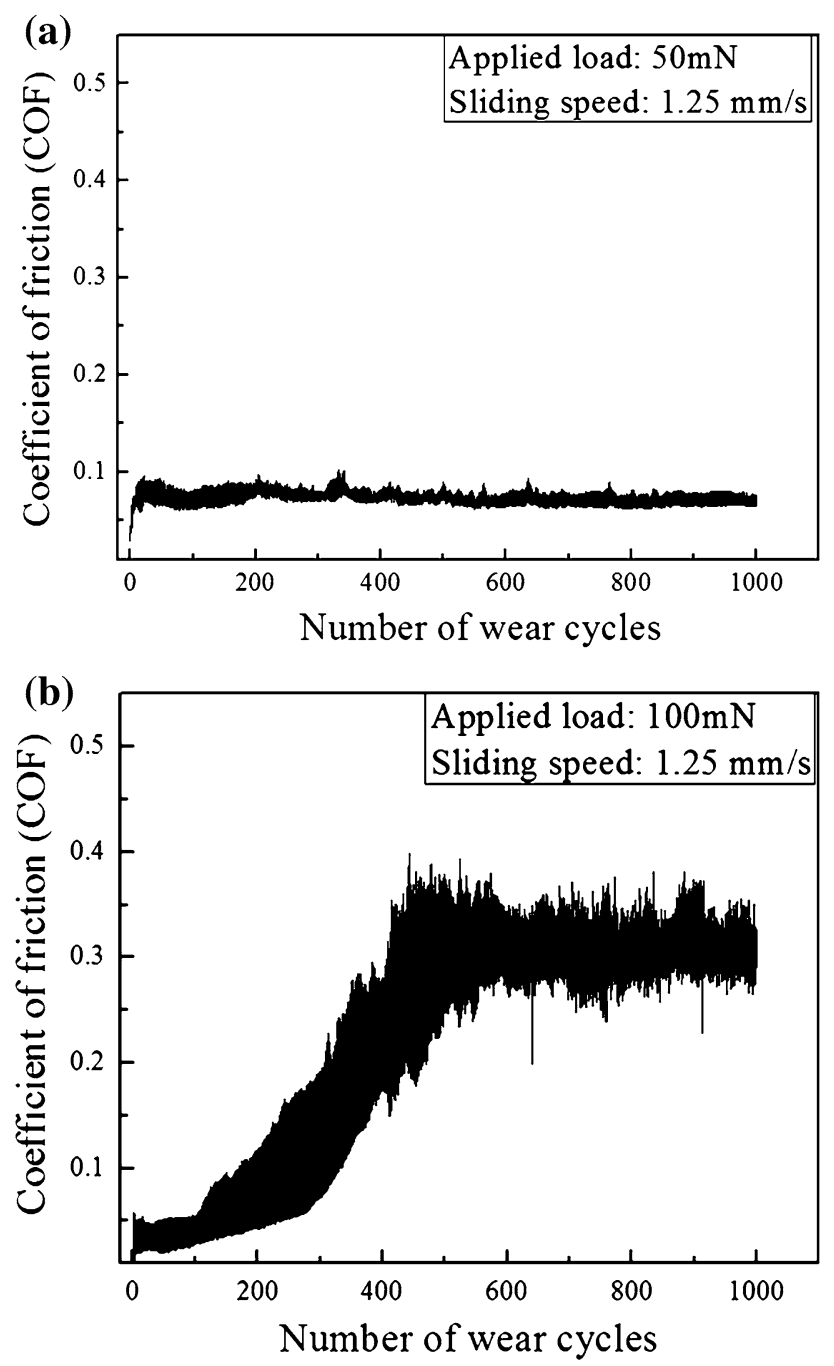

Fig. 2 Coefficient of friction of martensitic NiTi SMA as a function of wear cycles when tested under sliding wear mode: a under an applied load of $50 \mathrm{mN}$ and $\mathbf{b}$ under an applied load of $100 \mathrm{mN}$
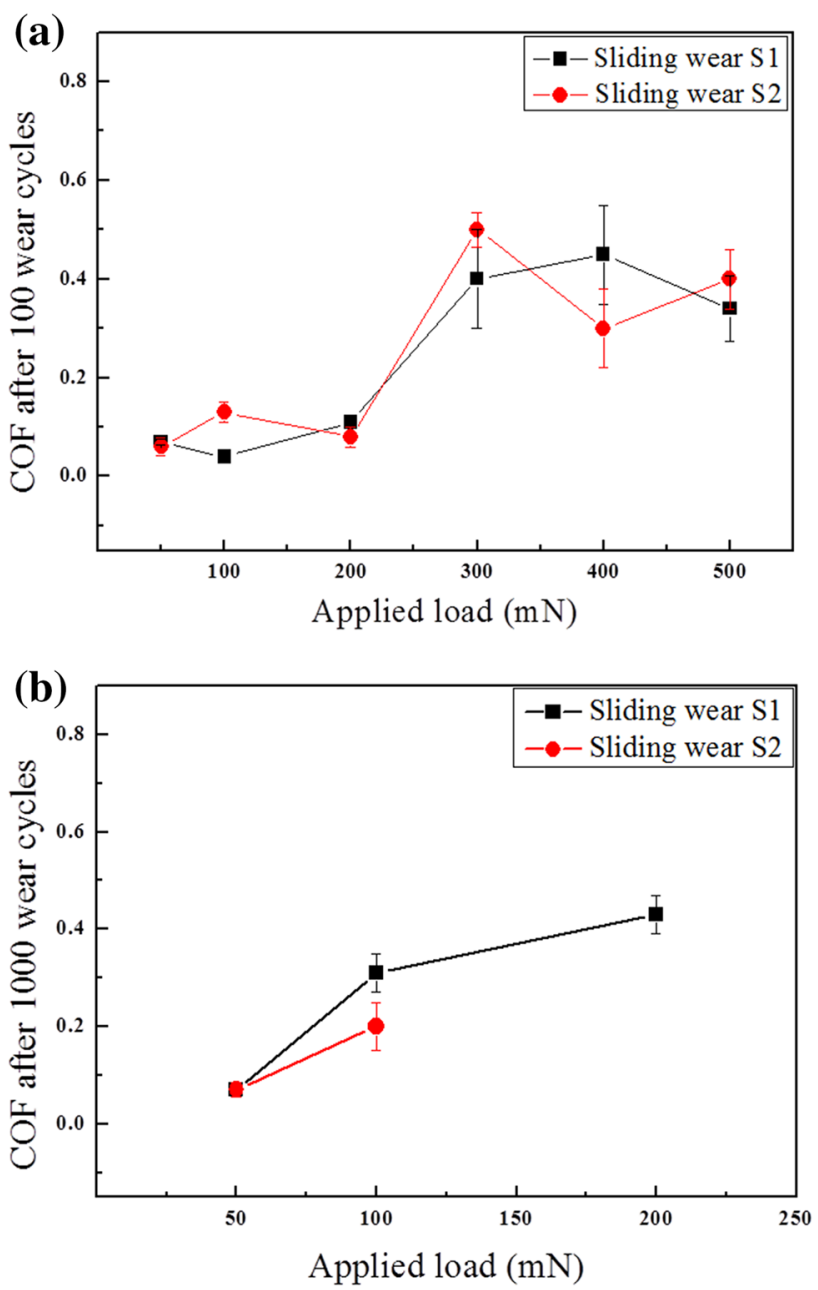

Fig. 3 Coefficients of friction of martensitic NiTi SMA as a function of applied load when tested under sliding wear mode at two different speeds (see Table 1 for details): a after 100 wear cycles and $\mathbf{b}$ after 1000 wear cycles

coefficient of friction (100 wear cycles) and stabilized coefficient of friction (1000 wear cycles) are used.

When tested under $50 \mathrm{mN}$, the coefficient of friction had remained at about 0.07 for 1000 wear cycles (Fig. 2a). With increasing the applied load to $100 \mathrm{mN}$, the coefficient of friction had increased to about 0.3 after 450 wear cycles (Fig. 2b). Thereafter, it had stabilized at this value for up to 1000 wear cycles.

Under sliding wear tests, the initial coefficient of friction (100 wear cycles) as a function of applied load was found to show two regions (Fig. 3a). When tested under lower loads of 50, 100, and $200 \mathrm{mN}$, coefficients of friction had remained below 0.1 for both sliding speeds $\mathrm{S} 1$ and $\mathrm{S} 2$. However, when tested under the loads of 300, 400, and 500 $\mathrm{mN}$, coefficients of friction had much increased to values varied between 0.3 and 0.5 .

The stabilized coefficients of friction taken from data after 1000 wear cycles are summarized in Fig. 3b. When 
tested under a load of $50 \mathrm{mN}$, the coefficient of friction had stabilized at around 0.07 at the sliding speeds of S1 and S2. When tested under $100 \mathrm{mN}$, the coefficient of friction had stabilized at around 0.32 at $\mathrm{S} 1$, while it was around 0.2 at $\mathrm{S} 2$. When tested under $300 \mathrm{mN}$, the stabilized coefficient of friction had increased to about 0.43 at S1. Meanwhile, the test under speed S2 was stopped before 1000 wear cycles due to severe instability.

\section{(2) Surface wear features}

After each wear test, the corresponding surface wear features were examined using laser confocal microscope (Fig. 4). Figure 4a, b presents the surface wear features after wear tests under the sliding speeds of $1.25 \mathrm{~mm} / \mathrm{s}$ (S1) and $2.5 \mathrm{~mm} / \mathrm{s}(\mathrm{S} 2)$, respectively. When tested under sliding speed $\mathrm{S} 1$ and a load of $50 \mathrm{mN}$, a large number of asperities were embossed on the track region after 1000 wear cycles. This special wear feature was named as "crown-like" structure [19]. When the applied load was increased to 100 $\mathrm{mN}$, the height of the crown-like structure was increased. With further increasing the load to $200 \mathrm{mN}$, some deep tracks cutting into the surface occurred at the bottom of the crown-like structure. This is consistent with the increasing trend of coefficient of friction when the applied load is increased. When tested under the loads of 300, 400, and $500 \mathrm{mN}$, wear tests were stopped before 1000 wear cycles were reached due to severe instability. However, a large amount of debris and tracks was found (Fig. 4a), suggesting that severe wear had occurred.

When tested under a sliding speed of S2 (Fig. 4b) and a load of $50 \mathrm{mN}$, insignificant amount of surface asperity was observed. When the applied load was increased to 100 and $200 \mathrm{mN}$, a crown-like structure was formed. When the load was further increased to 300, 400, and $500 \mathrm{mN}$, surfaces were severely damaged and a large amount of debris was produced.

More detailed surface wear features were revealed using a scanning electron microscopy (SEM) as shown in Fig. 5. When tested under a load of $50 \mathrm{mN}$, the track region was composed of areas with light surface damage. When tested under a load of $100 \mathrm{mN}$, clear wear tracks and small asperities were found.

\section{Austenitic NiTi SMA}

\section{(1) Coefficient of friction}

Wear tests were performed on the NiTi SMA plate which is in austenitic state at testing temperature. Similar to the previous case of martensitic sample, the coefficients of friction as a function of applied load and sliding speed at 100th and 1000th wear cycles are summarized in Fig. 6.
As shown in Fig. 6a, at a sliding speed of $\mathrm{S} 1$, under the loads of 25,50 , and $75 \mathrm{mN}$, the initial coefficients of friction were at around $0.06,0.09$, and 0.04 , respectively. When the load was increased to $100 \mathrm{mN}$, the initial coefficient of friction reached around 0.17 . With further increasing the load to 200 and $300 \mathrm{mN}$, initial coefficients of friction had further increased to about 0.51 and 0.47 , respectively, which indicates remarkable change in the deformation mechanism.

When tested at a higher sliding speed of S2, the initial coefficient of friction had remained below 0.1 with increasing the applied load. For the test under $75 \mathrm{mN}$, the initial coefficient of friction had reached around 0.15 . This value is comparatively high and it was likely caused by high vibration in the medium-load cantilever since this load has approached its upper limit. The initial coefficient of friction was highly unstable when tested under high loads and low sliding speed.

As to the stabilized coefficient of friction, under a load of $25 \mathrm{mN}$, it had stabilized at around 0.13 and 0.07 at $\mathrm{S} 1$ and $\mathrm{S} 2$, respectively (Fig. 6b). When tested under $50 \mathrm{mN}$, the coefficient of friction had stabilized at around 0.09 at both the sliding speeds of S1 and S2. When tested under $75 \mathrm{mN}$, the coefficient of friction had stabilized at about 0.08 at speed S1. However, at speed S2, the wear test was stopped before reaching 1000 wear cycles due to severe instability. For the tests under $100 \mathrm{mN}$, the coefficient of friction had stabilized at around 0.29 (S1) and 0.35 (S2). Tests under the loads of 200 and $300 \mathrm{mN}$ were forced to stop before reaching 1000 wear cycles due to severe instability.

It was noted that for the tests under high applied loads $(200,300 \mathrm{mN})$, the initial coefficient of friction is much lower when a high sliding speed (S2) is used. Whether or not this behavior is associated with local temperature rise which increased the critical stress for SIMT and wear resistance requires further investigation.

\section{(2) Surface wear features}

After each test, the surface wear features corresponding to coefficients of friction shown in Fig. 6 were examined using laser confocal microscope as shown in Fig. 7. Under an applied load of $25 \mathrm{mN}$ and at a sliding speed of $\mathrm{S} 1$, a small amount of asperities that embossed on surface was observed (Fig. 7a). When tested under the loads of 50, 75, and $100 \mathrm{mN}$, significantly increased amount of asperities was found. Furthermore, with increasing the applied load, the height and width of the crown-like structure had increased significantly. This is consistent with the increasing trend in the coefficient of friction. However, when tested under the applied loads of 200 and $300 \mathrm{mN}$, surfaces were severely damaged. Deep tracks and a large amount of debris were observed after 150 wear cycles under $200 \mathrm{mN}$ or 100 wear cycles under $300 \mathrm{mN}$. Meanwhile, the coeffi- 
(a)
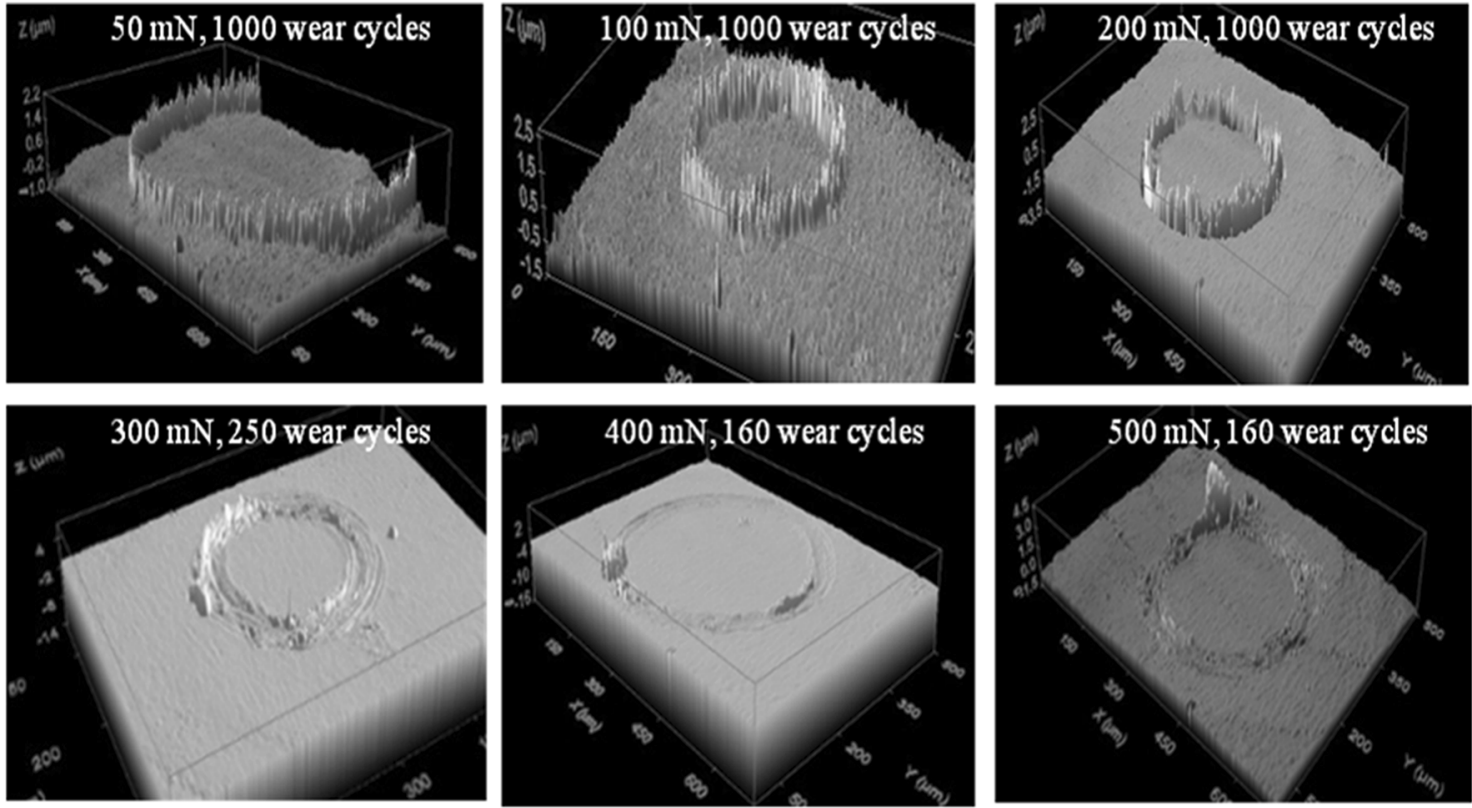

(b)
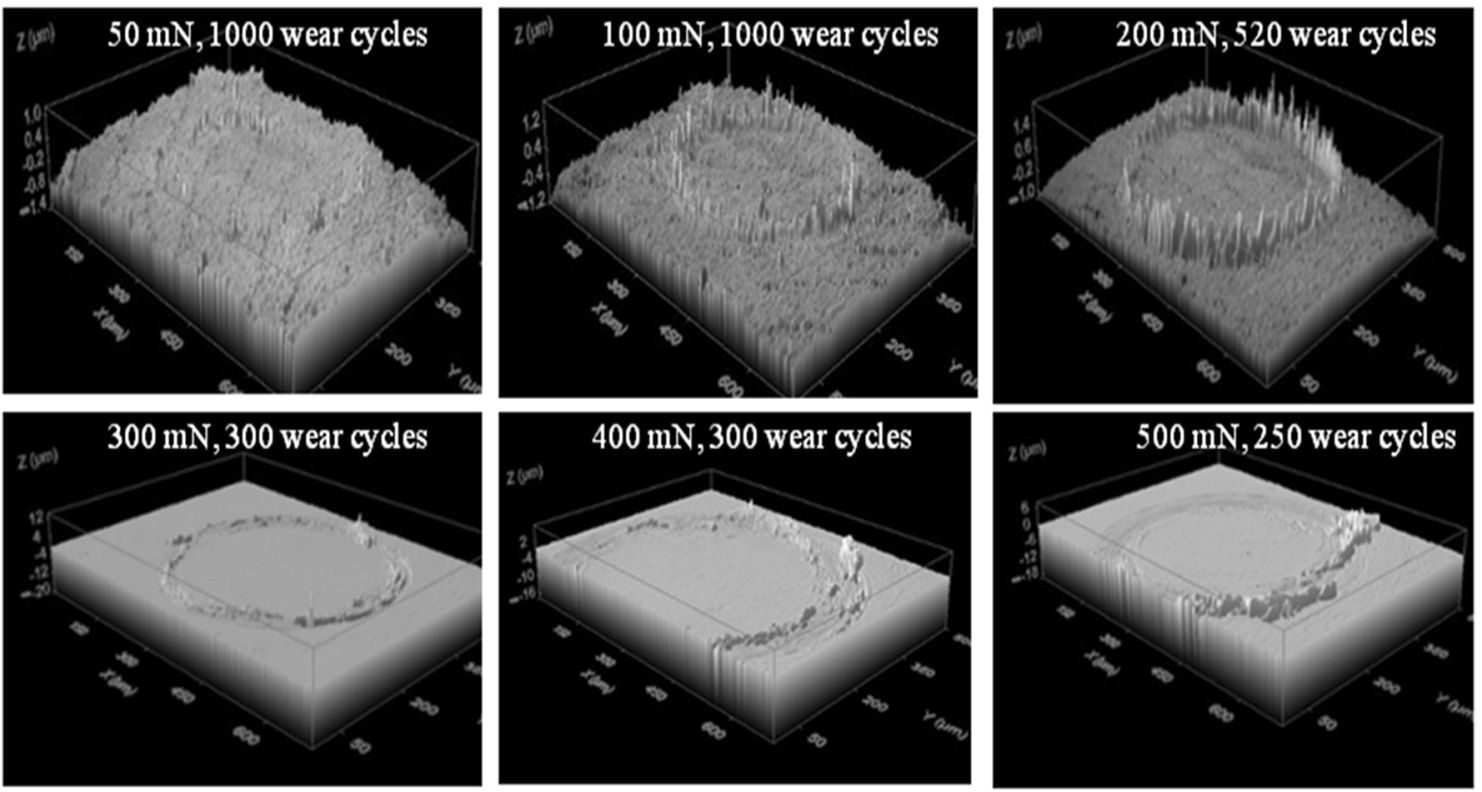

Fig. 4 3D confocal microscopic images of worn surfaces of martensitic NiTi SMA as a function of applied load, wear cycles, and sliding speeds indicated: a at a sliding speed of $1.25 \mathrm{~mm} / \mathrm{s}$ and $\mathbf{b}$ at a sliding speed of $2.5 \mathrm{~mm} / \mathrm{s}$

cient of friction was highly unstable, suggesting that severe surface wear had occurred.

When the sliding speed was increased to S2, under 25 $\mathrm{mN}$, no visible wear track was found after 1000 wear cycles (Fig. 7b). With increasing the applied load to 50, 75, and $100 \mathrm{mN}$, crown-like structures were found. When tested under a load of $200 \mathrm{mN}$, a significant amount of surface damage was found after 880 wear cycles. Further increasing the load to $300 \mathrm{mN}$, deep tracks and a large amount of debris were observed after 430 wear cycles.

\section{Wear Behavior Under Reciprocating Wear Mode}

Martensitic NiTi SMA

\section{(1) Coefficient of friction}

When martensitic NiTi SMAs were tested under reciprocating wear mode, different trends in the initial and stabilized coefficients of friction as a function of applied load and sliding speed were found and are shown in Fig. 8. 

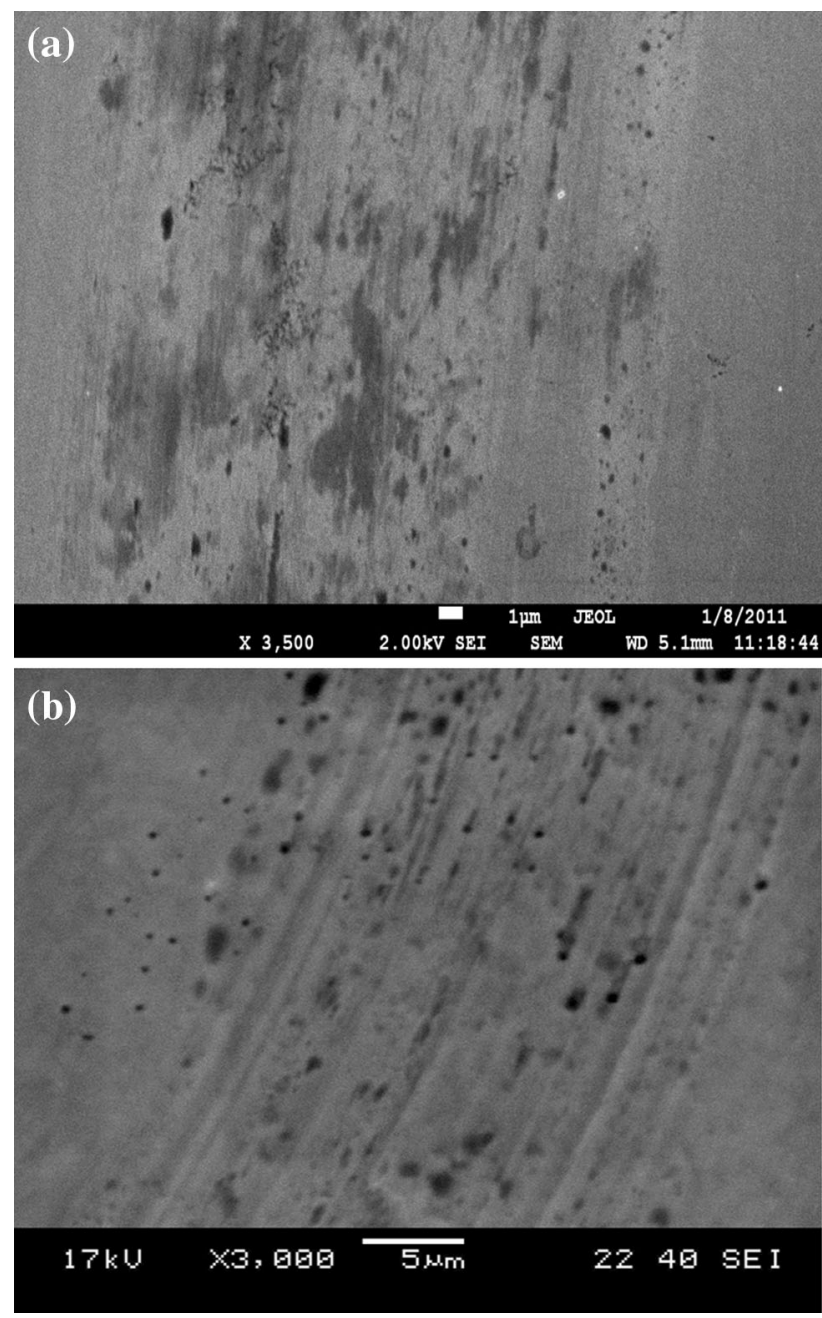

Fig. 5 SEM images showing surface wear features of martensitic NiTi SMA after tested under a $50 \mathrm{mN}$ and b $100 \mathrm{mN}$ after 1000 wear cycles

Coefficients of friction had remained at relatively low values as compared to those under sliding wear mode (Fig. 3). Initial coefficients of friction had varied at around 0.1 under different applied loads of up to $500 \mathrm{mN}$ and different sliding speeds (Fig. 8a). This value is comparable with the initial coefficient of friction when tested under low load (i.e., $50 \mathrm{mN}$ ) and sliding wear mode, but significantly lower than that under high loads and low sliding speed. With further increasing to 1000 wear cycles at speed S1, coefficients of friction had stabilized at around $0.15,0.19$, and 0.22 when tested under 50, 100, and $200 \mathrm{mN}$ (Fig. 8b), respectively. While at speed $\mathrm{S} 2$, coefficients of friction had stabilized at around 0.02 and 0.19 when tested under the loads of 50 and $100 \mathrm{mN}$, respectively. Overall, the above results suggested that under reciprocating wear mode the
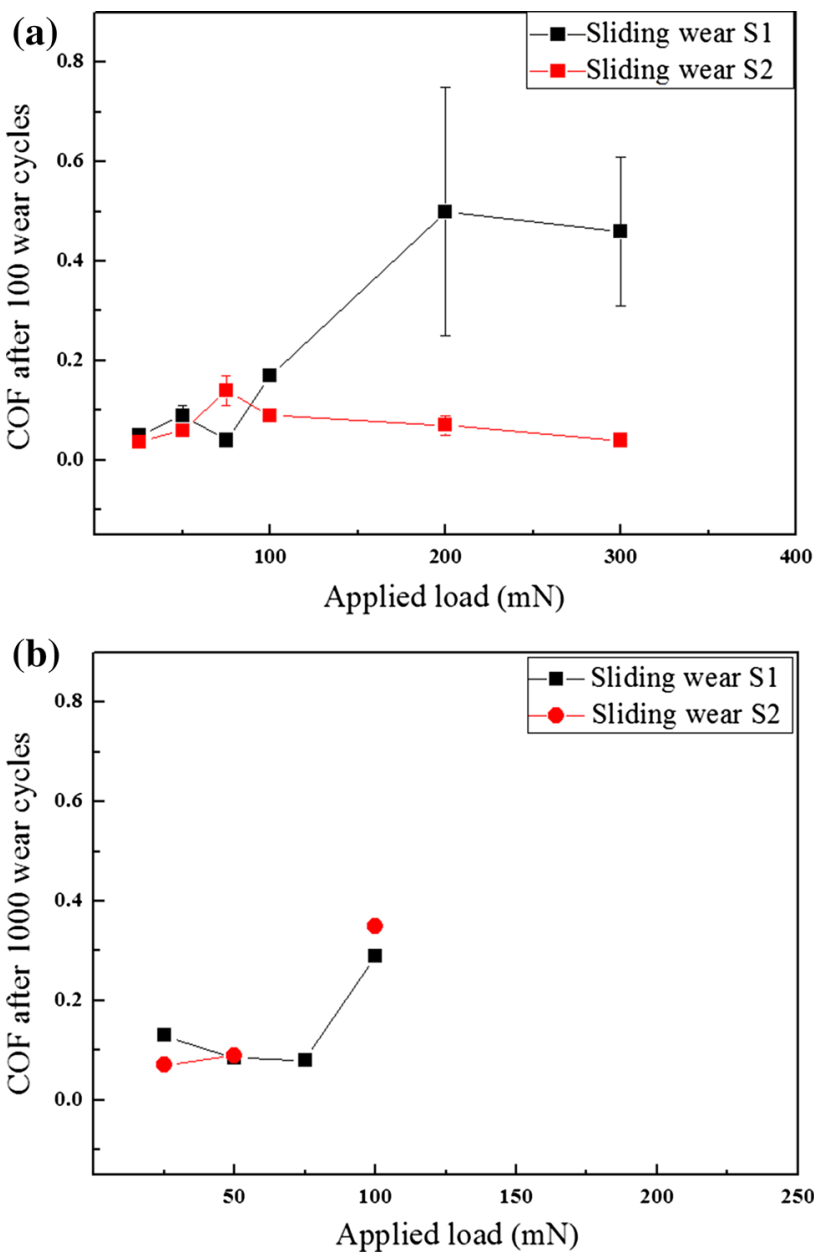

Fig. 6 Coefficient of friction of austenitic NiTi SMA as a function of applied load when tested under sliding wear mode: a after 100 wear cycles and b after 1000 wear cycles

material has better wear resistance than that under sliding wear mode.

\section{(2) Surface wear features}

Under reciprocating wear mode and after tested under different applied loads and sliding speeds, a small amount of asperities embossed on surface was observed as shown in Fig. 9. This is consistent with low values of the recorded coefficient of friction. Furthermore, when tested under an extremely high load of $500 \mathrm{mN}$ and at low sliding speed S1, the sample surface was flattened with little damage (Fig. 9a); however, a large wear scar was formed at a higher sliding speed of S2 (Fig. 9b). Wear process under such a high load was highly unstable. According to the surface wear features shown in Fig. 9, the overall surface damage is less when tested in reciprocating modes than that under sliding mode. This is consistent with the results of coefficient of friction. 
(a)
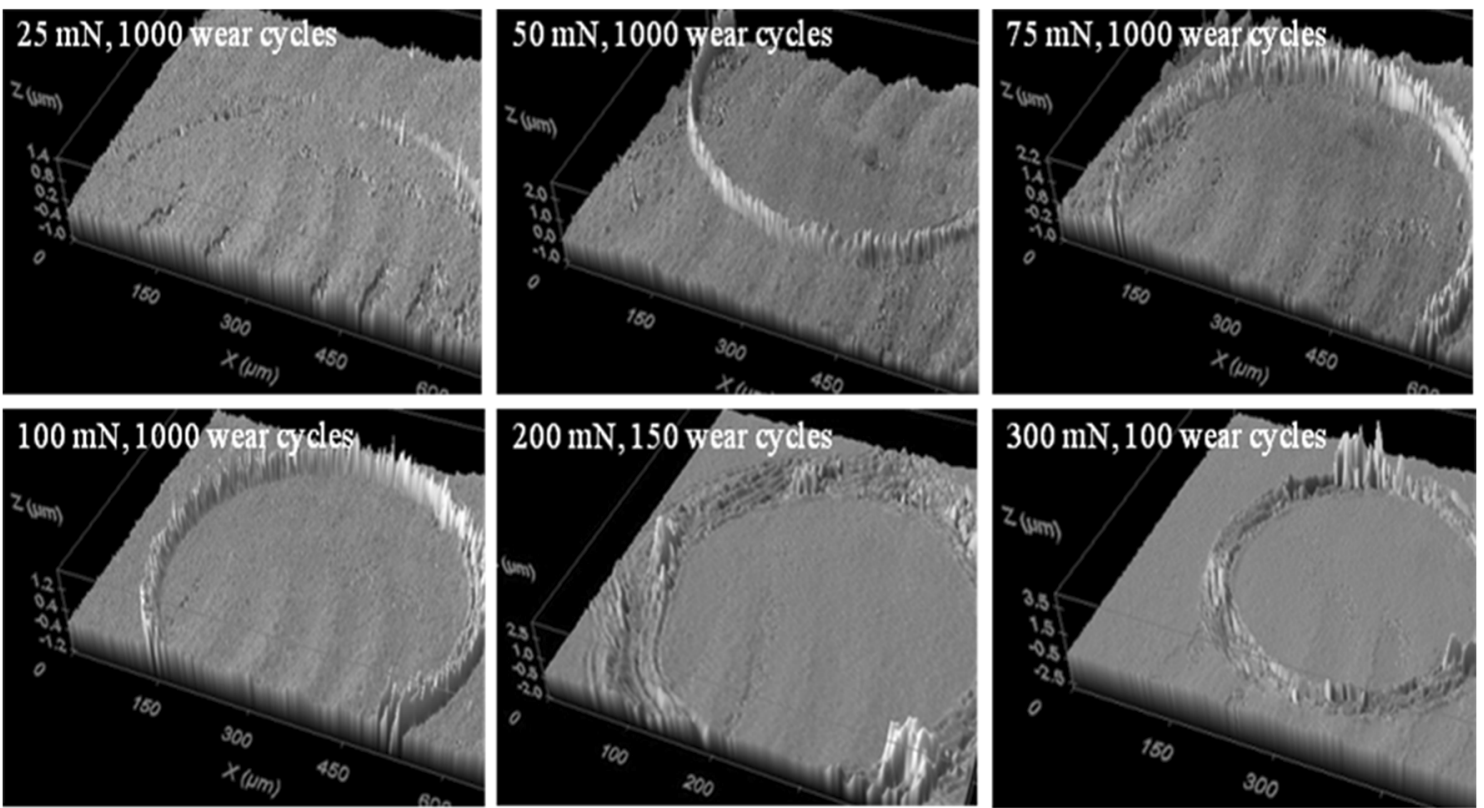

(b)
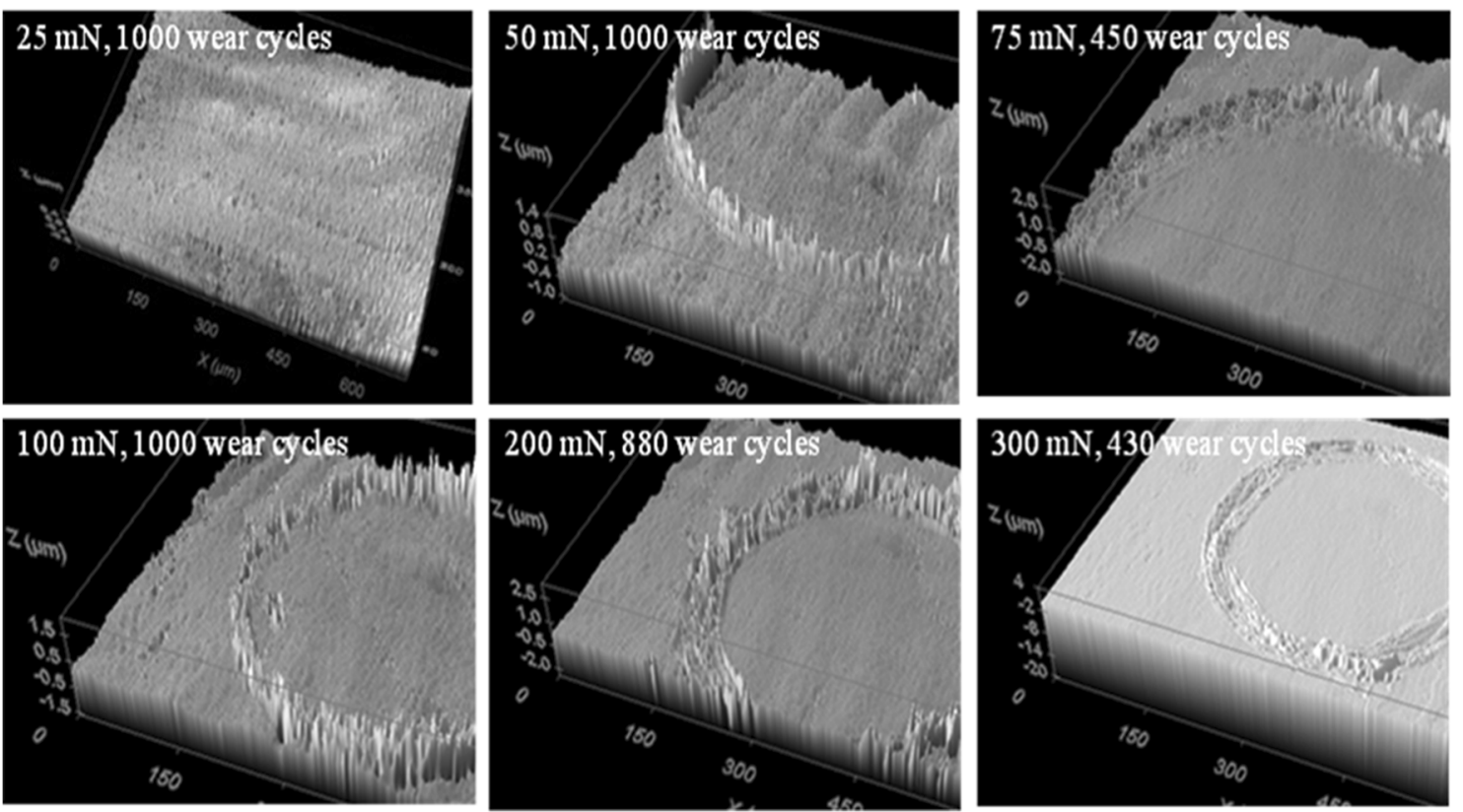

Fig. 7 3D confocal microscopic images of worn surfaces of austenitic NiTi SMA under sliding wear mode: a at a sliding speed of $1.25 \mathrm{~mm} / \mathrm{s}$ and $\mathbf{b}$ at a sliding speed of $2.5 \mathrm{~mm} / \mathrm{s}$

\section{Austenitic NiTi SMA}

\section{(1) Coefficient of friction}

When austenitic NiTi SMAs were tested under reciprocating wear mode, the coefficients of friction shown similar trends as compared to those under sliding wear mode. However, when tested under high applied load and low sliding speed, the initial coefficient of friction showed much higher value under sliding wear mode than that under reciprocating wear mode. In the early stage of wear test at a sliding speed of S1, the initial coefficient of friction had remained at about 0.07 when tested under loads of 25, 50, and $75 \mathrm{mN}$ (Fig. 10a). At a sliding speed of S2, the corresponding coefficients of friction were at around $0.14,0.06$, and 0.03 . When the applied load 

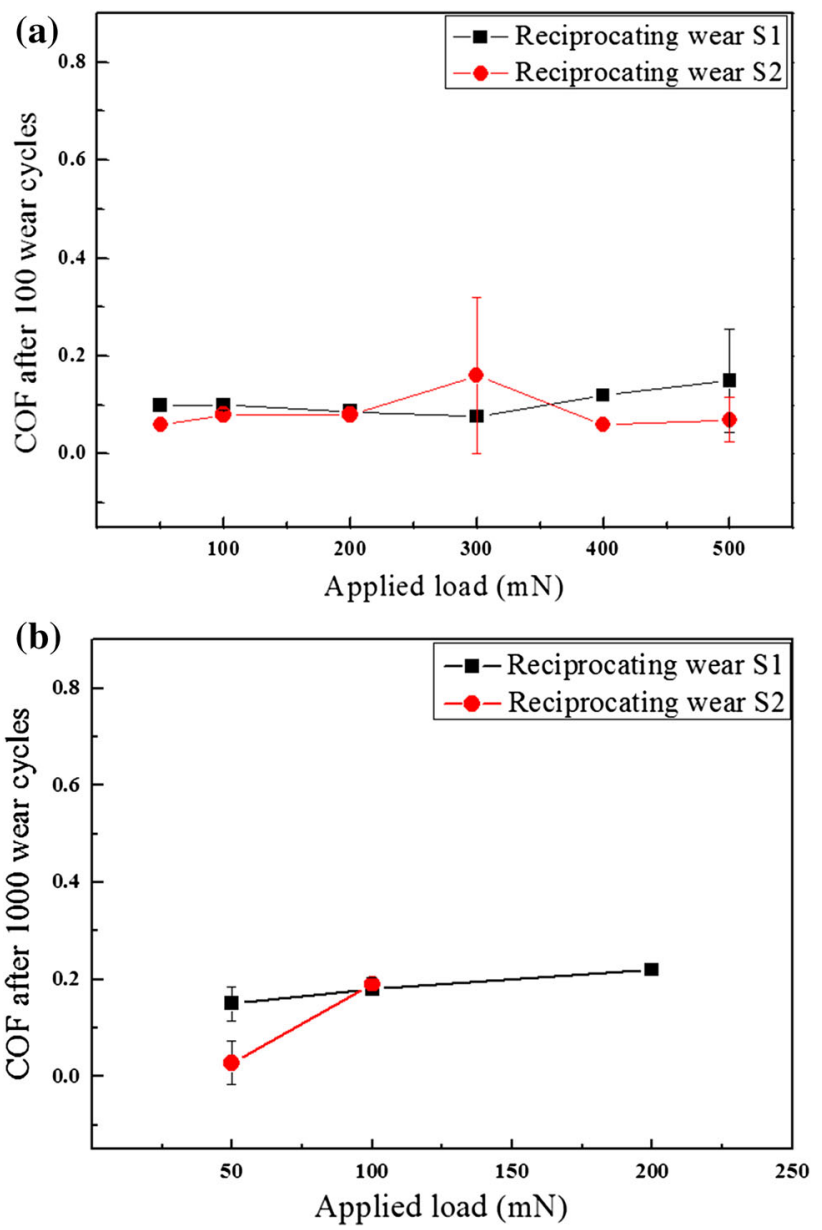

Fig. 8 Coefficients of friction of martensitic NiTi SMA as a function of applied load under reciprocating wear testing mode: a after 100 wear cycles and $\mathbf{b}$ after 1000 wear cycles

was increased to 100 and $200 \mathrm{mN}$, the initial coefficient of friction had increased to about 0.2. However, when at speed $\mathrm{S} 2$, the value was slightly below 0.1 . With further increasing the applied load to $300 \mathrm{mN}$, the initial coefficient of friction was increased to around 0.27 at speed S1. Test at speed S2 was stopped before reaching 1000 wear cycles due to high instability in the wear test. At higher sliding speed, low values of initial coefficient of friction may be caused by local temperature rise in the wear test that increases the yield stress of austenite.

After 1000 wear cycles, similar trends in the stabilized coefficients of friction were found for both sliding speeds S1 and S2 (Fig. 10b). When tested under low loads of 25, 50 , and $75 \mathrm{mN}$, at different sliding speeds, the stabilized coefficients of friction had remained in between 0.11 and 0.16 . In addition, when the load was increased to 100 and $200 \mathrm{mN}$, the coefficient of friction had reached about 0.25 . This clear trend further supports the change in the deformation mechanism. Furthermore, the coefficient of friction was more sensitive to the sliding speed in the early stage of the wear test. The stabilized coefficient of friction was strongly dependent on the applied load which is associated with different deformation mechanisms and will be discussed further in this report.

\section{(2) Surface wear features}

Figure 11 shows the surface features after various wear tests under reciprocating wear mode. Asperities that embossed on the worn surfaces were found similar after tested under different applied loads and sliding speeds. This is consistent with low values in the coefficient of friction, which indicates insignificant surface wear. When tested under high load $(300 \mathrm{mN})$, tests were stopped before reaching 1000 wear cycles, therefore the surface damage has remained insignificant.

\section{Discussion}

Wear behavior of NiTi SMA is dependent on the deformation mechanisms involved, while the deformation mechanism depends on the magnitude of the contact stress. If the applied load is fixed, the magnitude of contact stress increases with reducing the size of the counter ball used in wear test which can be estimated using Eq. (1). In order to investigate the wear processes due to different deformation mechanisms, a range of applied load needs to be selected which leads to different levels of contact stresses. Since the selection of applied load in the wear test depends on the size of the counter ball, in the present study, we have fixed the size of the counter ball for all tests in order to have comparable results.

\section{Effect of Deformation Mode on the Wear Behavior of Martensitic NiTi SMA}

When stressed, the deformation of martensitic NiTi SMA proceeds in four stages, namely (I) elastic deformation of twinned martensite, (II) martensite variant reorientation leading to detwinned martensite, (III) elastic deformation of detwinned martensite, and (IV) plastic deformation of detwinned martensite. In addition, in NiTi SMA, similar deformation sequences were reported when tested under compression and tension, while stronger strain hardening effect was found when tested under compression [20].

When the applied load is below $50 \mathrm{mN}$, the coefficient of friction had remained at low values (around 0.1-0.15) for both sliding and reciprocating wear modes. When tested under $50 \mathrm{mN}$, the estimated contact stress slightly exceeded the critical stress for martensite detwinning in the present sample (determined from tension test). Hence below 50 $\mathrm{mN}$, elastic deformation of twinned martensite likely 
(a)
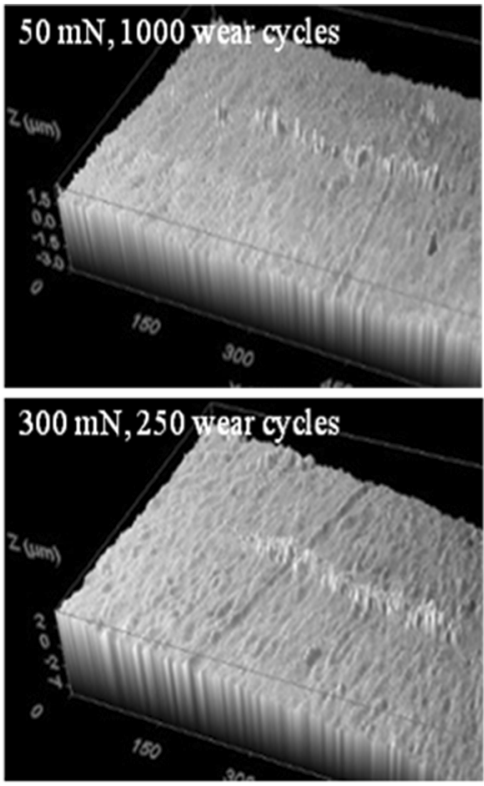

(b)
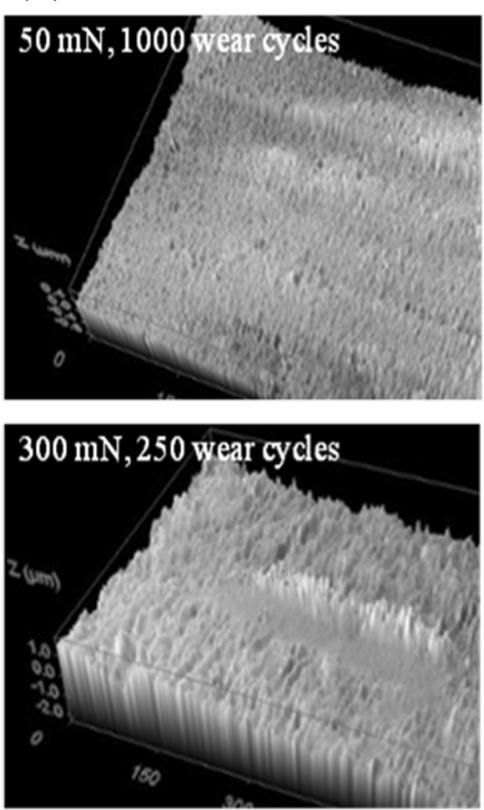
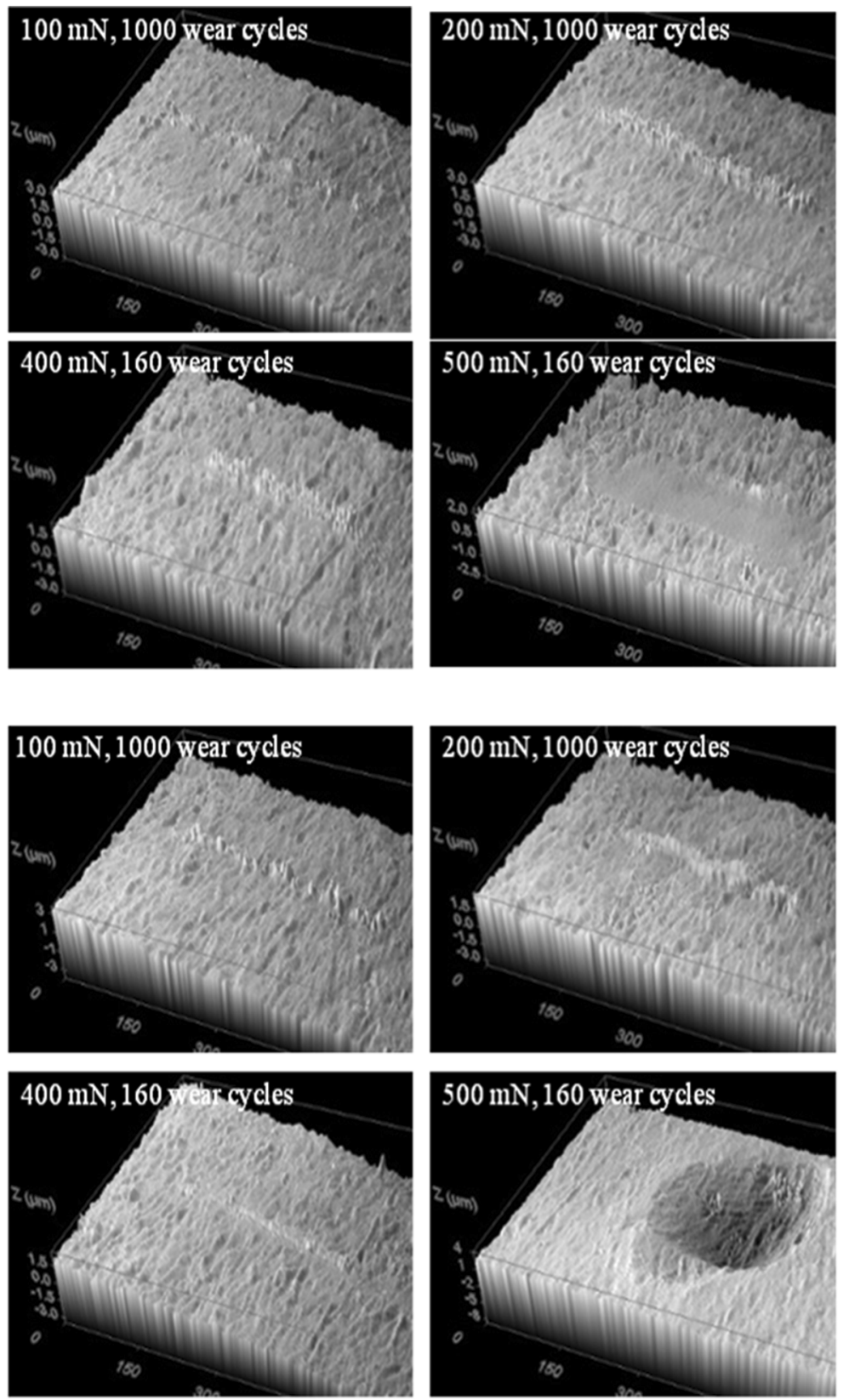

Fig. 9 3D confocal microscopic images of worn surfaces of martensitic NiTi samples after wear test in reciprocating mode under different applied loads and wear cycles indicated: a at a sliding speed of $1.5 \mathrm{~mm} / \mathrm{s}$ and $\mathbf{b}$ at a sliding speed of $2.5 \mathrm{~mm} / \mathrm{s}$

dominated the wear processes in both testing modes. Reversible elastic deformation is not sensitive to the deformation mode since insignificant plastic strain accumulation occurred.

When the applied stress is increased so that the martensite reorientation dominates the deformation process, the wear behavior became sensitive to the deformation mode. When tested under sliding wear mode, a unidirectional load/stress is applied since the alumina counter ball moves all the way in one direction, single martensite variant in the most favorable orientation grows in each grain [21]. The elastic energy stored in the selfaccommodated martensite can be released through deformation, which contributes to the martensitic stabilization effect $[22,23]$. Dislocations can also be generated both inside the martensite plates and along the grain boundaries due to mismatch in the orientations [24]. With the contact stress further increased but below the yield stress of detwinned martensite, deformation can be accommodated through further martensite variant reorientation [22, 25]. 

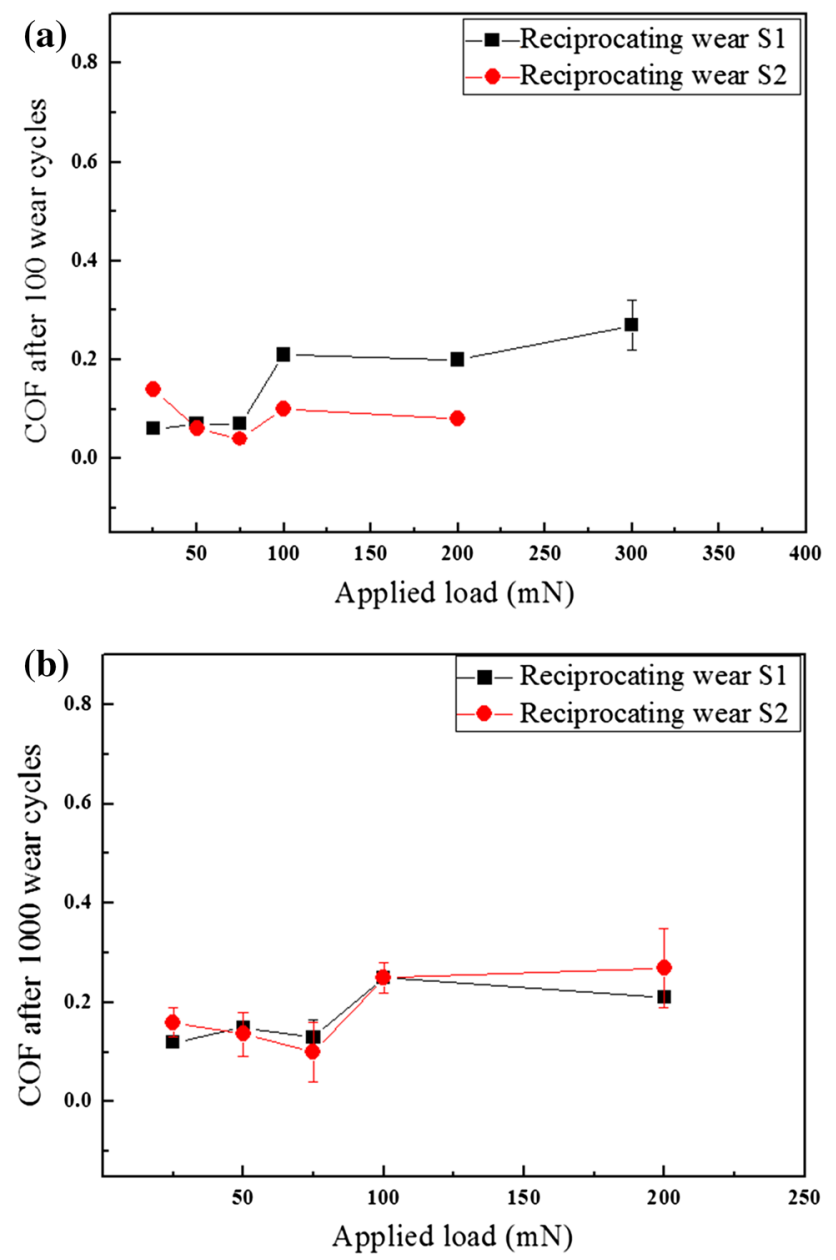

Fig. 10 Coefficients of friction of austenitic NiTi SMA as a function of applied load when tested under reciprocating wear mode: a after 100 wear cycles and $\mathbf{b}$ after 1000 wear cycles

Majority of self-accommodated twinned martensite changes to a reoriented configuration.

During repeated wear cycles, once the reorientation of martensite is completed, further deformation can only proceed through elastic deformation and even plastic deformation of detwinned martensite. Since the stress in the contact area immediately beneath the alumina ball is much higher than the average contact stress, it is likely to induce local plastic deformation although the area could be very small. With increasing the wear cycles, the plastic deformation will accumulate and lead to increased amount of surface damage.

In the early stage of wear, deformation can be effectively accommodated through martensite variant reorientation process. Plastic strain accumulation can be retarded, resulting in insignificant surface damage. For example, when tested under 100 and $200 \mathrm{mN}$ in sliding wear tests (Fig. 3), after 100 wear cycles, the coefficients of friction had remained below about 0.12 . This relatively low value is comparable to that under $50 \mathrm{mN}$, suggesting that insignificant plastic strain accumulation has occurred in the initial stage of wear test. With increasing wear cycles, plastic strain accumulates. This results in a significant growth in surface damage. For example, when tested under the applied loads of 100 and $200 \mathrm{mN}$, with increasing the wear cycles to 1000 cycles, the coefficient of friction had reached about 0.3 and 0.4 .

In a polycrystalline martensitic NiTi SMA, it is commonly known that an internal elastic stress field can be created due to the constraint of neighboring grains in the self-accommodating process. During deformation, such internal elastic stress can be relieved through martensite reorientation. However, a new internal stress field can be created by the externally applied stress, which is in the same direction as the reoriented martensite variants, i.e., the same direction as the external shape change $[23,26]$. When tested under reciprocating wear mode, the deformation is repeated in opposite directions. As a result, the internal stresses formed in the opposite directions tend to cancel each other, therefore increasing the reversibility of the martensite variants and retarding the plastic strain accumulation. This could lead to delayed surface damage and hence low values of the coefficient of friction. This might explain why under the reciprocating mode the coefficient of friction was lower than that under sliding mode and had less surface damages. For example, when tested under reciprocating wear mode and under the applied loads of 100 and $200 \mathrm{mN}$ (Fig. 8), the coefficient of friction after 1000 wear cycles was about 0.18 and 0.22 , respectively. These values are much lower than those under sliding wear mode. Observation of much less surface damage under reciprocating wear mode as compared to that under sliding wear mode further supports this argument (Figs. 4, 9).

\section{Effect of Deformation Mode on the Wear Behavior of Austenitic NiTi SMA}

The deformation mechanisms that dominate the wear process of austenitic NiTi SMA have been discussed in a previous publication [27]. When the applied stress is below the critical stress for SIMT (stage I), elastic deformation dominates the wear process, thus no significant plastic strain accumulation occurs in repeated wear cycles. When tested under the loads of 25,50 , and $75 \mathrm{mN}$, the estimated average contact stresses were below the critical stress for SIMT. Hence for both sliding and reciprocating wear modes, the coefficient of friction had remained at low values (below about 0.15 ) for up to 1000 wear cycles (Figs. 6, 10).

When the applied stress approaches the critical stress for SIMT (stage II), preferentially oriented stress-induced martensite is formed in austenite grains in the early stage of 
(a)
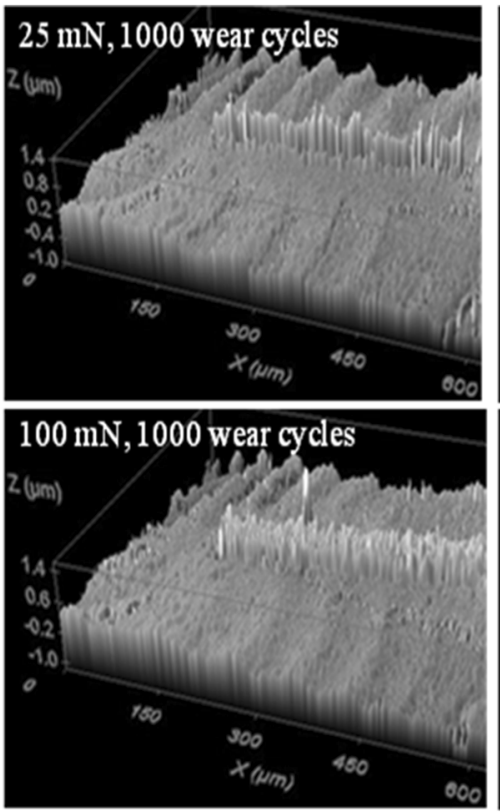

(b)
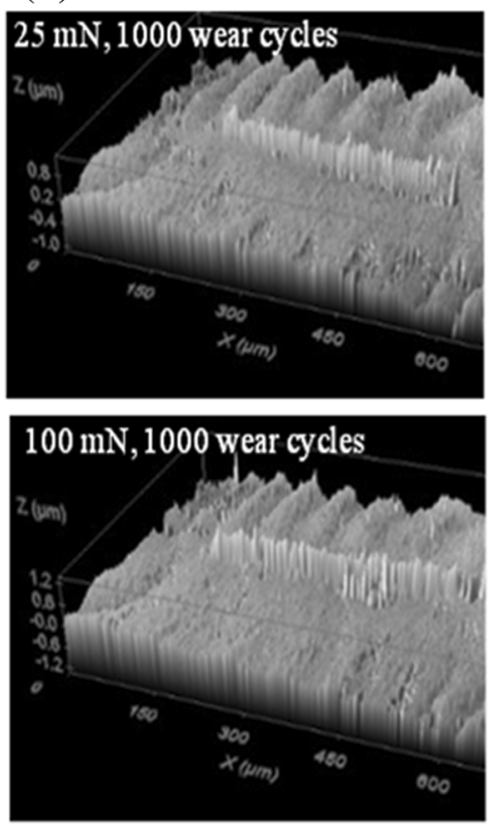
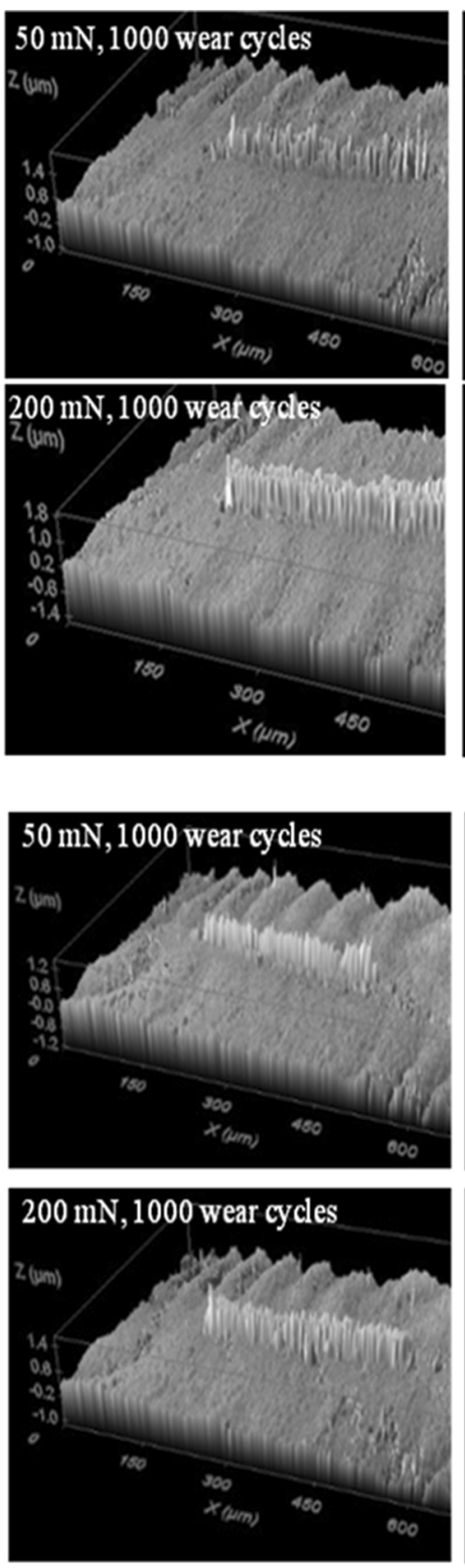
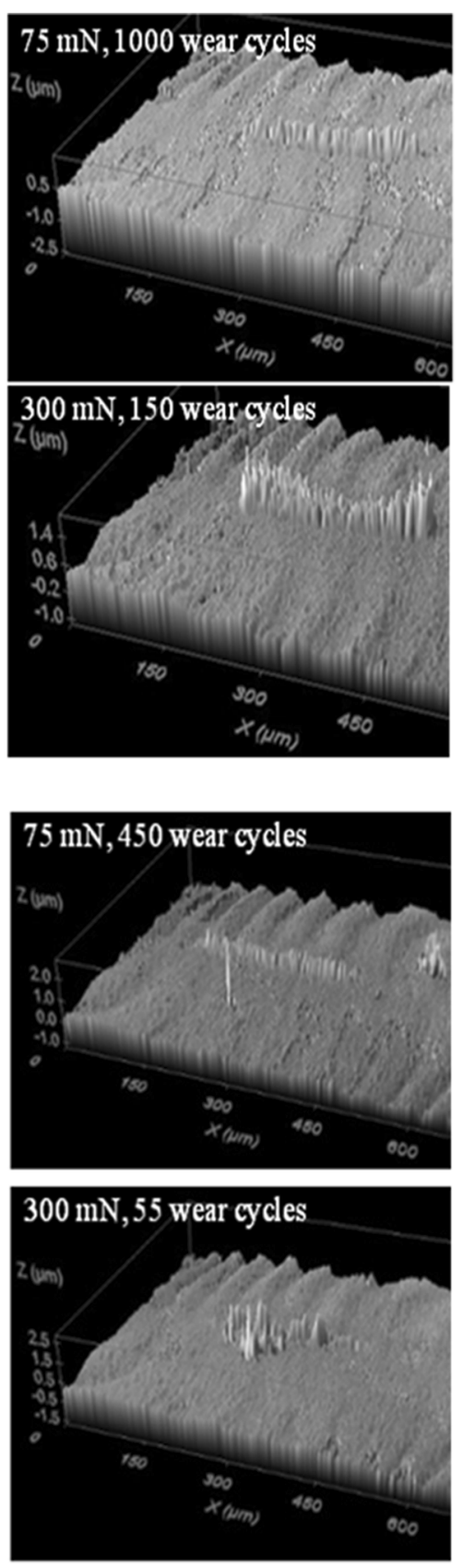

Fig. 11 3D confocal microscopic images of worn surfaces of austenitic NiTi SMA after wear tests under reciprocating wear mode with conditions of applied load and wear cycles indicated: $\mathbf{a}$ at a sliding speed of $1.5 \mathrm{~mm} / \mathrm{s}$ and $\mathbf{b}$ at a sliding speed of $2.5 \mathrm{~mm} / \mathrm{s}$

wear test [28]. With further increasing wear cycles, neighboring grains begin to reorient. Grains that are unfavorably oriented require higher applied stress in inducing phase transformation. Furthermore, internal stress field due to orientation mismatch among the neighboring grains can only be released by plastic deformation [26]. Defects such as dislocations and vacancies can be generated in compensation to reorientation of grains. Part of martensite variants are "locked" or "pinned" by internal stress field [29]. Furthermore, movement of phase boundaries for the reverse transformation can be hindered by deformation-induced defects [30].

With further increasing the applied stress to stage III, elastic deformation of SIM dominates the wear process. Upon unloading, the critical stress for the reversed SIMT decreases due to the stabilization of martensite by internal stress field which was induced during the stress-induced phase transformation process [31]. This agrees with the 
stress-strain curve shown in Fig. 1b when the deformation strain ranges from 4 to $10 \%$.

When the SIMT and elastic deformation of SIM dominate the wear process, in the early stage of wear, deformation can be accommodated through SIMT in the most favorably oriented grains. Thus insignificant surface wear occurred. This could be supported by low values in the initial coefficients of friction when tested under an applied load of $100 \mathrm{mN}$ (Fig. 6). Under sliding wear mode, the coefficient of friction was around 0.17 (S1) and 0.09 (S2) after 100 wear cycles. These values are comparable to the low coefficients of friction observed when tested under 25 and $50 \mathrm{mN}$, where elastic deformation dominated the wear process. Using transmission electron microscope (TEM) with an in situ deformation technique, Jiang and colleagues [32] have reported reversible movement of the martensitematrix interfaces in a loading-unloading cycle when the applied stress was below the yield stress of the SIM. This further supports the insignificant plastic strain accumulation at the beginning of the wear process. With increasing wear cycles, reorientation of unfavorably oriented grains is accompanied by further plastic strain accumulation. This is in agreement with the significant increase in the coefficient of friction with increasing wear cycles. For example, when tested under $100 \mathrm{mN}$ and after 1000 wear cycles, the coefficient of friction had stabilized at about 0.29 (S1) and 0.36 (S2).

On the other hand, the internal stress field originated from mismatch of reoriented grains can be effectively relieved by applying a reciprocating stress. The stabilized SIM by internal stress field can be released when the external stress is applied in opposite direction under reciprocating mode. This process increases the reversibility of SIMT and reduces plastic strain accumulation. For example, when tested under $100 \mathrm{mN}$, the coefficient of friction in the early stage of wear was about 0.2 (S1) and $0.1(\mathrm{~S} 2)$. These values are comparable to those tested under sliding wear mode, since the internal stress field has yet been developed in the early stage of wear test under sliding mode. After 1000 wear cycles in reciprocating wear tests, the coefficients of friction were stabilized at about 0.26 at different sliding speeds. These stabilized coefficients of friction were much lower than those under sliding wear mode.

Beyond yield stress of SIM, plastic deformation of SIM occurs (stage IV) and a large number of dislocations are generated. However, some shape recovery can be induced by applied reciprocating stress which contributes to slightly lower values of the coefficient of friction in the early stage of wear. For example, when tested under 200 and $300 \mathrm{mN}$ at low sliding speed (refer to Table 1), the initial coefficient of friction was about 0.5 under sliding wear mode. However, it was about 0.27 when tested under reciprocating wear mode. This significant difference further suggests that, under reciprocating load, the surface damage is significantly reduced, likely due to a relief of internal stress field which promotes the reversibility of stress-induced phase transformation.

\section{Conclusions}

The present research has investigated the effect of deformation mode on the wear behavior of NiTi SMA in both martensitic and austenitic states. One is a sliding wear mode in which the NiTi surface was deformed unidirectionally for up to 1000 wear cycles. Another one is a reciprocating wear mode in which the NiTi surface was deformed under alternating stresses in opposite directions for up to 1000 wear cycles. The testing parameters also include varying the applied load and sliding speed. Coefficient of friction and surface wear features were used to characterize the surface wear damage. In general, the testing conditions can be grouped into low-load condition and high-load condition, while the surface wear can be grouped into initial stage (around 100 wear cycles) and later stage where the coefficient of friction is stabilized (around 1000 wear cycles). Based on the investigation results, the following major conclusions can be drawn:

1. When tested under low-load condition, the wear process of martensite and austenite was not sensitive to the deformation mode. However, when tested under high-load condition, the wear process of martensite and austenite is strongly deformation mode dependent.

2. For the martensitic NiTi SMA, when tested under high loads, sliding wear mode causes more surface damage as compared to reciprocating wear mode. This was tentatively explained due to the inversed direction of applied load in the reciprocating mode that promotes the reversibility of martensite variant reorientation process. This retarded the plastic strain accumulation and hence led to less surface damage.

3. For the austenitic NiTi SMA, when tested under high loads, reciprocating wear mode showed significantly better wear resistance as compared to sliding wear mode. This was tentatively explained because, when tested under opposite stresses, the internal stress that stabilized the stress-induced martensite may be partially relieved. This helps promote reverse transformation of SIM and shape recovery, hence retarding the plastic strain accumulation and surface damage process.

4. The present results further suggest that in order to accurately assess/predict the wear behavior of $\mathrm{NiTi}$ SMA bio-medical devices, due to complex deformation modes involved in practices, one would need to take into consideration the effect of deformation mode 
on the wear behavior of these devices. Reciprocating wear mode can improve their service life as far as wear is concerned.

Acknowledgments L. Yan is grateful for the research scholarship provided by Nanyang Technological University.

\section{References}

1. Miyazaki S (1998) Medical and dental applications of shape memory alloys. In: Otsuka K, Wayman C (eds) Cambridge University Press, Cambridge

2. Miyazaki S, Fukutsuji S, Taira M (1993) Application of Ti-Ni shape memory alloys to partial dentures. In: Proceedings of the international conference on martensitic transformations (Icomat92). pp 1235-1240

3. Geetha $\mathrm{M}$ et al (2009) Ti based biomaterials, the ultimate choice for orthopaedic implants: a review. Prog Mater Sci 54(3):397-425

4. Chu PK (2006) Bioactivity of plasma implanted biomaterials. Nucl Instrum Methods Phys Res, Sect B 242(1):1-7

5. Shabalovskaya SA (1995) On the nature of the biocompatibility and on medical applications of NiTi shape memory and superelastic alloys. Bio-Med Mater Eng 6(4):267-289

6. Silberstein BM, Gunter V (2000) Shape-memory implants in spinal surgery: long-term results (experimental and clinical studies). In: Shape memory implants. Springer, Berlin, pp 147-152

7. Fischer H, Vogel B, Welle A (2004) Applications of shape memory alloys in medical instruments. Minim Invasive Ther Allied Technol 13(4):248-253

8. Li CY et al (2007) In vivo histological evaluation of bioactive NiTi alloy after 2 years implantation. Mater Sci Eng, C 27(1): $122-126$

9. Li DY (1996) Wear behaviour of TiNi shape memory alloys. Scripta Mater 34(2):195-200

10. Li DY (2000) Exploration of TiNi shape memory alloy for potential application in a new area: tribological engineering. Smart Mater Struct 9(5):717-726

11. Clayton P (1993) Tribological behavior of a titanium nickel-alloy. Wear 162:202-210

12. Qian LM, Sun QP, Zhou ZR (2005) Fretting wear behavior of superelastic nickel titanium shape memory alloy. Tribol Lett 18(4):463-475

13. Qian LM, Zhou ZR, Sun QP (2005) The role of phase transition in the fretting behavior of NiTi shape memory alloy. Wear 259(1-6):309-318

14. Qian LM et al (2007) Nanofretting behaviors of NiTi shape memory alloy. Wear 263(1-6):501-507

15. Qian LM, Sun QP, Zhou ZR (2008) The role of martensite reorientation in the fretting behaviour of nickel titanium shape memory alloy. Proc Inst Mech Eng $\mathbf{J} \quad \mathbf{J}$ Eng Tribol 222(J7):887-897

16. Johnson KL (1985) Contact mechanics. Cambridge University Press, Cambridge

17. Otsuka K, Ren X (2005) Physical metallurgy of Ti-Ni-based shape memory alloys. Prog Mater Sci 50(5):511-678

18. Brinson LC, Schmidt I, Lammering R (2002) Micro and macromechanical investigations of CuAlNi single crystal and CuAlMnZn polycrystalline shape memory alloys. J Intell Mater Syst Struct 13(12):761-772

19. Yan L, Liu Y, Liu EJ (2013) Wear behaviour of martensitic NiTi shape memory alloy under ball-on-disk sliding tests. Tribol Int $66: 219-224$

20. Liu Y (2001) Detwinning process and its anisotropy in shape memory alloys. In: Smart materials and MEMS. International Society for Optics and Photonics

21. Liu Y et al (2000) On the deformation of the twinned domain in NiTi shape memory alloys. Philos Mag A 80(8):1935-1953

22. Liu Y, Tan G, Miyazaki S (2006) Deformation-induced martensite stabilisation in [100] single-crystalline Ni-Ti. Mater Sci Eng, A 438:612-616

23. Piao M et al (1993) Mechanism of the A s temperature increase by pre-deformation in thermoelastic alloys. Mater Trans, JIM 34(10):919-929

24. Tan G, Liu Y (2004) Comparative study of deformation-induced martensite stabilisation via martensite reorientation and stressinduced martensitic transformation in NiTi. Intermetallics 12(4):373-381

25. Liu Y (2004) Mechanistic simulation of deformation-induced martensite stabilisation. Mater Sci Eng, A 378(1):459-464

26. Liu Y, Favier D (2000) Stabilisation of martensite due to shear deformation via variant reorientation in polycrystalline NiTi. Acta Mater 48(13):3489-3499

27. Yan L, Liu Y (2015) Wear behavior of austenitic NiTi shape memory alloy. Shap Mem Superelasticity 1:1-11

28. Miyazaki S, Otsuka K, Suzuki Y (1981) Transformation pseudoelasticity and deformation behavior in a Ti-50.6 at\% Ni alloy. Scr Metall 15(3):287-292

29. Brinson LC, Schmidt I, Lammering R (2004) Stress-induced transformation behavior of a polycrystalline NiTi shape memory alloy: micro and macromechanical investigations via in situ optical microscopy. J Mech Phys Solids 52(7):1549-1571

30. Lin HC et al (1991) The effects of cold rolling on the martensitic transformation of an equiatomic TiNi alloy. Acta Metall Mater 39(9):2069-2080

31. Lin HC, Wu SK (1993) Determination of heat of transformation in a cold-rolled martensitic TiNi alloy. Metall Trans A 24(2):293-299

32. Jiang XP et al (1997) In situ observation of stress-induced martensitic transformation and plastic deformation in TiNi alloy. Mater Sci Eng, A 238(2):303-308 